\title{
Engaging students in paleontology: the design and implementation of an undergraduate-level blended course in Panama
}

\author{
Catalina Pimiento $1,2,3,4^{*}$
}

\begin{abstract}
Despite the fact that Latin-American countries present ideal environments to train young scientists, most of these countries lack local scientific capacity. Here I describe the design and implementation of an undergraduate-level blended course on paleontology. The course was taught in 2012 to 10 biology majors from the University of Panama and it had three main foci: (1) a design grounded in a theoretical framework that supports meaningful learning; (2) the application of concepts and skills to the region where the students live, making the learning experience relevant and authentic; and (3) a strong research and science-communication component that allowed students to experience real-life situations (i.e. those commonly faced by scientists throughout their careers). These components contributed synergistically to engage students with paleontology, a field not formally taught in their country. This work can be applied to different disciplines in science and to different levels in students' scientific training.
\end{abstract}

Keywords: Geology, Nature of science, Online learning, Role-playing

\section{Introduction}

Blended learning is the thoughtful integration of the strengths of synchronous, face-to-face experiences and asynchronous, online learning activities (Garrison and Kanuka 2004; Graham 2013). Evaluations have shown that when the design of the blended curriculum is grounded in a theoretical framework that supports authentic learning experiences, the implementation of blended environments supports meaningful learning more effectively than completely online or face-to-face environments (US Department of Education 2010).

Community of inquiry (herein, CoI) is a theoretical framework commonly used to conceptualize blended learning and that leads to transformative learning experiences. A CoI consists of a cohesive and interactive group of learners who critically analyze, construct and confirm knowledge through connections, collaboration, reflection

\footnotetext{
*Correspondence: pimientoc@ufl.edu

${ }^{3}$ Smithsonian Tropical Research Institute, Box 2072, Balboa, Panama Full list of author information is available at the end of the article
}

and discourse (Garrison and Arbaugh 2007). A CoI is created by framing the learning process in the social nature of education (community component) and the construction of meaning through personal choice (inquiry component). Furthermore, it can be reinforced by making learning experiences purposeful (about investigating problems as opposed to memorizing solutions), open (with freedom to express ideas) and disciplined (reinforcing attitudes and skills that enhance critical thinking and to continuous life-long learning) (Garrison and Kanuka 2004; Garrison and Arbaugh 2007).

Interestingly, the conceptual foundations of $\mathrm{CoI}$ are also fundamental components of science. Science is largely conducted by widespread networks of professionals that collaborate to systematically collect and analyze data, test hypotheses and effectively communicate their results (Michaels et al. 2008). Accordingly, scientists are constantly engaged in discussions that allow them to produce knowledge. Consequently, science students not only need to learn concepts in a effective way, but in order to be better prepared to face the challenges of 
their professional lives, they also need to understand the Nature of Science (NOS), i.e. how to create knowledge and the methodology used to communicate and validate it (e.g. Lederman 1983, 1992).

Even when the benefits of blended teaching and learning of science have been previously documented (e.g. US Department of Education 2010; Pane et al. 2013; Coulson et al. 2014), to my knowledge, there are no reports in the literature of theoretically grounded blended courses in Paleontology. Here I describe the use of the $\mathrm{CoI}$ as the theoretical framework to design and implement a blended course on the paleontology of Panama. The course was intended to engage students with this field of science (which is not formally taught in the country), and hence, to contribute to build local scientific capacity. Accordingly, the design and implementation of this course takes advantage of the potential of blended environments to support meaningful learning, the scientific expertise of the author of this work, and the tremendous opportunities presented by recent intensified research activities in Panama in the field of paleontology.

\section{Design}

Online and face-to-face activities in a learning environment have different advantages and thus complement each other. For instance, face-to-face communication lays the foundation for a CoI whereas online media enable it to be sustained by flexible, largely asynchronous communication. Therefore, when designing a blended course, two important challenges are to choose appropriate media to promote meaningful learning (Graham 2013), and to evaluate the known media based on course objectives (Garrison and Kanuka 2004) (Fig. 1). The following

\begin{tabular}{|l|}
\hline $\begin{array}{l}\text { General Objective: To engage } \\
\text { students in Paleontology. } \\
\text { Specific Objectives: } \\
\text { 1. Students will be able to } \\
\text { describe, schematize, explain, } \\
\text { discuss and interpret the most } \\
\text { relevant concepts on the } \\
\text { paleontology of Panama. } \\
\text { 2. Students will be able to } \\
\text { reflect on their learning } \\
\text { process. } \\
\text { 3. Students will be able to } \\
\text { apply research and communi- } \\
\text { cation skills in order to develop } \\
\text { and share scientific projects. }\end{array}$ \\
\hline
\end{tabular}

Fig. 1 Course objectives [aided by Bloom's Taxonomy (Bloom et al. 1956)]. Details on the paleontological concepts referred in the objective 1 can be found in Fig. 4 strengths of synchronous and asynchronous online and face-to-face environments were taken into consideration for the design of this course:

\section{Face-to-Face Activities}

Face-to-face activities are useful to introduce and explore problems, as well as to encourage students in brainstorming, debating and role-playing, given that during these activities, verbal and visual communication exchange gives students the ability to connect personally, strengthening the Col. If used in the initial stages of the course, this familiarity can then be translated in online environments. Icebreakers in the first session of the course are good examples of welcoming face-to-face activities that help develop camaraderie among learners. In a blended course, initial sessions of the course should include faceto-face demonstrations of the different media to be used, so students understand and value the purpose of the blended activities (Garrison and Vaughan 2008). This can be facilitated by the use of tutorials on the different media. Youtube offers a large array of online video-tutorials on how to use Web 2.0 (e.g. blogs and wikis) that can be presented to the class.

Although traditional lectures have been criticized for being unsuitable for diverse classrooms (Demetriadis and Pombortsis 2007; Davis et al. 2009; Folley 2010) they can be engaging and efficient for the communication of concepts and expert knowledge. In a blended environment, videoconferences with expert guest-speakers allow students to interact with scientists from different parts of the world in real-time. This experience provides students with authentic scientific information from original sources, which is pivotal for learners to take the lead in constructing their own knowledge. Moreover, such lectures can be interactive if students have the opportunity to pose questions to the guest-speakers, and can be enhanced by pre-activities that include students' revising the content beforehand and sending questions to the scientists. Experts can also adapt their presentations based on students' knowledge and curiosity, which can potentially lead to a student-centered approach. These interactions with experts can result in gains in students' science interest (Gottesman and Hoskins 2013).

Scientific articles provide students with the essential scientific concepts that they need to understand and incite inquiry. The benefits of article reading can be enhanced when they are: (a) discussed immediately in class, because it is possible to explore and clarify false assumptions, concepts, or connections (Garrison and Vaughan 2008, p. 46), and (b) combined with interactions with authors, because it both demystifies the scientific literature and humanizes science (Hoskins and Stevens 2009). Finally, field trips are good instances to introduce 
topics, focus interest, and engage students. They also provide students with the basis for conducting research. This research can ultimately lead to positive transformations in students' scientific engagement (Harrison et al. 2011).

\section{Online Interactions}

Studies have shown that students have positive attitudes towards the use of online environments in blended courses (Tselios et al. 2011). Such environments provide learners with opportunities to individually reflect on and explore questions, as well as to construct resolutions collaboratively. This is important, as collaboration, discourse, and interaction play a key role in knowledge construction and the building of a CoI. Moreover, online written communication might allow some participants to better project themselves socially (Garrison and Vaughan 2008).

Blogs can be used for students to reflect on their learning in a non-intimidating way (Garrison and Vaughan 2008; Richardson 2010), especially if students' interactions via comments are also requested. Blogging exposes students to the social process of discussing questions, exploring controversies, and questioning ideas. Such processes are common in science. Furthermore, blogs enhance students' perceived learning and sense of community (Richardson 2010; Halic et al. 2010), and allow the instructor to assess engagement.

In science there will always be complex concepts presented at a high cognitive level, where synthesis is important to construct meaningful learning. Face-to-face activities are desirable in these cases. However, certain online activities can help students to synthesize content by creating schemas of linked concepts in a collaborative and dynamic way. Wikis are efficient, flexible and userfriendly platforms for collaboration, knowledge creation and student interaction (Schwartz et al. 2004). These are fundamental components of a successful CoI. Thus, the use of class wikis in which students collaboratively construct maps of important concepts can help reaching a deeper understanding of complex ideas, while reinforcing the collaboration in the CoI.

\section{The Blend}

Taking into consideration the described strengths of the different media and learning strategies, the next step was to thoughtfully "blend" face-to-face and online environments (Fig. 2). Four interconnected phases were taken into consideration [for a more detailed explanation see Garrison and Vaughan (2008), pp. 112-128] to support the progression of inquiry:

(A) Before the next face-to-face activity: in this first phase, triggering events to provoke inquiry take

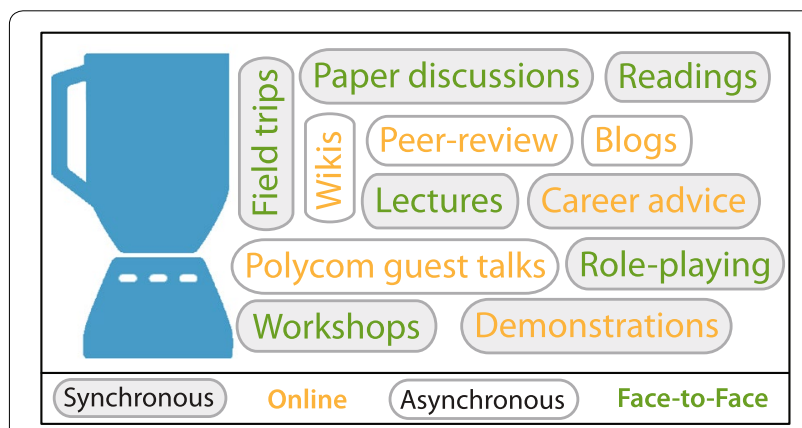

Fig. 2 Activities to be implemented in the blended. They were "blended" in the course following the theoretical framework that supports authentic learning experiences

place. Examples include readings and demonstrations.

(B) During face-to-face activities: in this second phase, interactive lectures and assessment allow learners to understand the content.

(C) Between face-to-face activities: in the third phase, online collaboration (e.g. via blogs or wikis) permits students to reflect on the concepts and learn in a collaborative way, reaching deeper understanding.

(D) The next face-to-face activities: in the fourth and final phase, class discussions and role-playing provide resolution and finalize the learning process.

\section{Implementation}

This course was taught in the spring of 2012 to 10 senior biology students from the University of Panama (UP), Republic of Panama. Even though biology students of the UP take standard coursework in biological sciences (e.g. general biology, chemistry, botany, zoology, ecology, physiology, evolution, genetics, etc.), as well as alternative classes in specialized subjects (e.g. vertebrates, invertebrates, tropical ecology, geography, histology, etc.), they lack any paleontology background, as this discipline is not formally taught either in the UP, or any university in the country. This is also the case throughout much of Latin America. Paradoxically, Panama has a great potential for the study of paleontology because it preserves a fossil record that captures key moments in the history of ancient biodiversity. Additionally, the construction, and most recently, the widening of the Panama Canal has attracted a diverse array of investigators who are conducting exciting research projects along paleontological sites (Kays 2014). This paradox inspired the instructorwho is one of the researchers working in the area-to focus the course on Panama in order to arouse students' curiosity using a relevant topic, hoping it would engage them with the field of paleontology. 
The course was taught in the facilities of the Smithsonian Tropical Research Institution (STRI), where most of the scientific research in Panama is done, and where the infrastructure for a blended course was provided (e.g. classrooms with Polycom ${ }^{\circledR}$ videoconference system and multimedia equipment; and a library with computers and Internet access). Students ranged from 20 to 22 years of age and included six females and four males. They were required to have completed all coursework for the third year to sign up for this class (i.e. general biology, chemistry, physics, botany, zoology, mathematics, microbiology, statistics, general ecology, genetics, evolution and physiology). The course was taught for 16 weeks, with one session of $3 \mathrm{~h} /$ credits per week. It consisted of four main sections covering different objectives (Fig. 3) and included two field trips. All students had computer access in both the UP and STRI, and most of them also had a computer at home. The course was completely (i.e., all assignments, lectures and activities) taught in Spanish; however, most of the readings were in English (see legend for Fig. 4).

\section{Introduction (Two Sessions)}

The first session of the course (Fig. 4) consisted of phases (B-D). During the face-to-face activity (phase B) students introduced themselves. Then they learned about the technologies to be used (e.g. wikis and blogs) in the class by watching tutorial videos on Youtube. In addition,

\begin{tabular}{|l|}
\hline Introduction: To recognize the \\
design of the blended course, \\
the technologies to be used, \\
and to identify the main \\
concepts in the study of the \\
paleontology of Panama. \\
Geology: To describe and \\
schematize the concepts in \\
geology that are most relevant \\
for the study of the ancient \\
biodiversity of Panama. \\
Paleontology: To explain, \\
interpret and discuss the \\
ancient biodiversity of Panama \\
while reflecting on their own \\
learning process. \\
Research Projects: To apply \\
research and communication \\
skills in paleontology.
\end{tabular}

Fig. 3 Course objectives by section [aided by Bloom's Taxonomy (Bloom et al. 1956)]. Details on the concepts referred can be found in the Additional file 1 and in Fig. 4

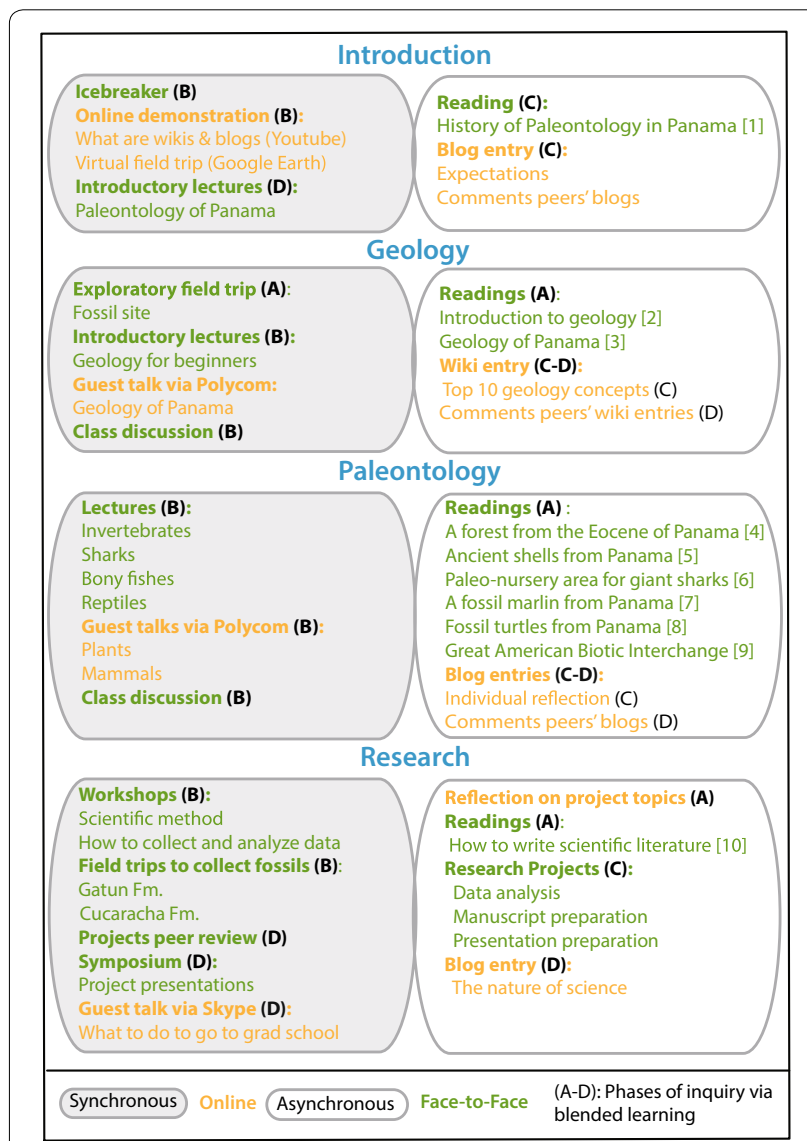

Fig. 4 Blended activities per section. The interconnected phases of inquiry via blended learning are: $A$ before the next face-to-face activity, $B$ during face-to-face activities, $C$ between face-to-face activities and $D$ the next face-to-face activities. Numbers in brackets refer to the readings as follows: [1] ODea et al. (2007), [2] Benton and Harper (2009), [3] Kirby et al. (2008), [4] Herrera et al. (2012), [5] Glaubrecht (2009), [6] Pimiento et al. (2010), [7] Fierstine (1978), [8] Cadena et al. (2012), [9] MacFadden (2006), [10] Valderrama (2005)

they were engaged in a virtual tour via Google Earth of the areas to be studied during the course. These demonstrations engaged students by promoting enthusiasm for the subject, and by helping them get a closer look at their environment using technology. Students seemed surprised to learn about the learning potential of these media and were excited to be able to use it for the class. All of them learned about wikis for the very first time in this course.

Between this and the next face-to-face session (phase C), students read an introductory article on the paleontology of Panama (Fig. 4). This was the only article they read in Spanish. They also started a blog in which they reflected on their course expectations. Although clarity was a requirement, no detailed instructions were provided on how to write blog entries, as this activity was 
intended to be informal and have a free conversationstyle. Finally, students posted comments in their peers' blogs. At this point, based on their first blog entry, students seemed to have low expectations for this course and were particularly surprised to have a young, Latin female as an instructor.

The second session consisted of the next face-to-face activity (phase D). Here, students attended an introductory lecture for $1 \mathrm{~h}$ in which they learned the basic concepts necessary to understand the ancient biodiversity of Panama (e.g. types of outcrops, age, types of fossils, history of paleontology in Panama, and major contributions). Lastly (and after a 15 min break), students were engaged in a 1-h class discussion about the subjects introduced. During the discussion, students were very curious about the types of fossils that have been discovered in recent years along the Panama Canal.

\section{Geology (Two Sessions) and Paleontology (Six Sessions)}

The second and third sections (Fig. 4) had similar design, except for the online-collaborative activities, and the field trip to a fossil site. In both sections, the phase before face-to-face sessions (phase A) involved the reading of scientific articles about the content, and submitting one (1) question that emerged during the readings. For the geology section, students also went on a fieldtrip in order to observe some of the concepts taught. This field trip took place in the late Miocene Gatun Formation (San Judas locality), which is a marine, shallow-water paleo-environment with abundant invertebrates, sharks and rays (e.g. Pimiento et al. 2013). An overview on the geology and paleontology of the fossil site was provided for about $25 \mathrm{~min}$. Then students spent about $3 \mathrm{~h}$ surface prospecting the area and collecting fossils. Most of these fossils were used for the research projects later in the semester and were then deposited in the collections of the STRI.

During the face-to-face sessions (phase B), students attended videoconferences with experts from the University of Florida in the US and lectures by STRI scientists. In both cases, they lasted $1 \mathrm{~h}$. Often, the guest-speakers giving the talk were also the authors of the articles read. The speakers had access to students' questions in advance and they covered them in their presentations. At the end of the lecture, students asked additional questions for 15 min. Students' questions were mostly regarding further clarification about the lecture. Finally, the class, as a group, discussed the articles, the questions and the lectures for about $1 \mathrm{~h}$. Most of discussions were related with the fossils in question (e.g. how and where to find them, how to date them, how to identify them, etc.). Students had a break of 15 min between the videoconference/lecture and the class discussion.
The phase between face-to-face sessions (phase C) was different in the geology and paleontology sections (Fig. 4). In the first, students created a collaborative wiki as a class in which they created a scheme of the most important concepts learned. Each student was required to contribute with 10 concepts and their definitions, and to link them with other concepts within the wiki. This facilitated synthesis while reinforced collaboration and students' interactions. Conversely, for the paleontology section, students posted a blog entry after every session. In these posts, students provided a thoughtful description of their learning process by reflecting about what they had learned, what they found confusing, and what they found most interesting. Students were instructed to not simply provide a list of concepts, and to catalogue them as learned, confusing and interesting; but to critically think about their learning. Accordingly, they were also asked to include the reasons why certain concepts were harder to digest than others, or why some were more interesting. In so doing, students were motivated to reflect about what systems they are most interested in, what provokes more curiosity, and what kind of scientists they would like to be.

In the final stage, (phase D: next face-to-face session), students were requested to comment on at least two of their peer's blogs, or wiki entries, engaging them in discussion and consensus. They also received feedback from the instructor about their posts. This feedback was based on whether or not students succeeded in providing authentic reflections. The criteria were used to produce this feedback included: (1) the student not only listed the concepts learned, still confusing, and interesting; but also included the reasons why certain concepts were learned differently relative to others, and (2) the student used this reflection to think about the kind of scientists they want to be in the future.

\section{Research (Five Sessions)}

For the last section of the course (Fig. 4), the before face-to-face sessions (phase A) consisted of sorting the research groups and themes. First, students individually revised their notes and reflected on what kind of research project they wanted to do. Based on that, we discussed the potential project themes and sorted the class into three groups with the following themes: invertebrates, sharks, and the fauna from the Panama Canal (Fig. 5). Each group had one mentor from STRI (including the instructor). All mentors were young Latin paleontology grad-students. Groups then brainstormed and decided on the topics to investigate within their theme.

During face-to-face sessions phase (phase B), students were engaged in two types of activities: 


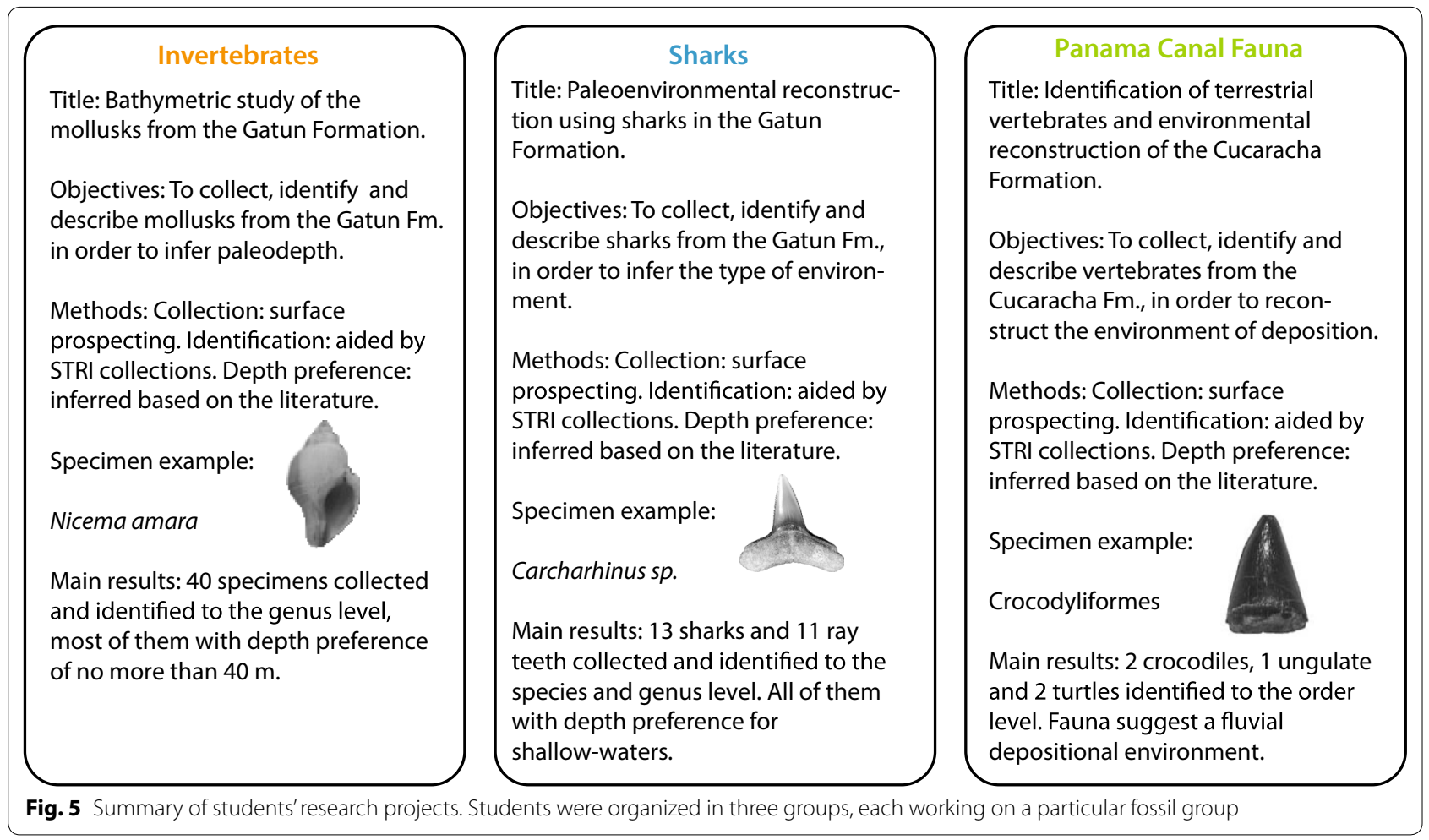

- A series of workshops on how to design, implement and communicate their research projects. Topics included how to design a research project, how to manage and analyze data, how to write a paper for a peer-review journal and how to present it in a professional conference. Each workshop consisted on a theoretical section in which the instructor gave a presentation on the different topics, and on practical section in which students designed their projects and started analyzing the data, writing their manuscripts and preparing the presentation of their results.

- One fieldtrip per research group to a fossil site. These field trips took place once students had designed their research projects. The field trips for the invertebrates and the sharks groups were to the late Miocene Gatun Formation, whereas for the Panama Canal group it was to the Miocene Cucaracha Formation (Figs. 4, 5). Research field trips lasted about $6 \mathrm{~h}$ in which students surface prospected the area and collected fossils for their projects.

Projects were entirely student-driven, as they decided on their topics and developed their researches independently (Fig. 5). Guidance, instructions and feedback were provided in the workshops. With regards to the manuscript, they also read an article on how to write scientific papers (Fig. 4). Such article provided the guidelines to prepare the document. As for the presentations, groups were instructed to give 15 min Power Point presentations in which all members of the group presented a section, and to answer questions from the audience for $5 \mathrm{~min}$. All activities and deliverables of this phase were followed up and completed between face-to-face sessions (phase C).

In the last stage (phase D, the next face-to-face sessions) students engaged in role-playing situations where they simulated being scientists. First, they played the role of authors and submitted their papers to a simulated peer-review journal. At the same time, other students played the role of reviewers and editors. After the "reviewers" commented on the manuscripts, the "editors" made a decision and sent the "authors" the revisions for them to make the appropriate changes. The peer-review process took place in the classroom, where I provided them with guidelines based on my own experience. I explained the process and provided examples of reviews of my own papers, and of reviews I have made of other papers. Students never heard of the peer-review process before; therefore, they were very interested and curious. They understood the process quickly, seemed to have enjoyed it, and did not face any major challenges.

Lastly, students played the role of scientists attending a professional symposium in which they presented their results (Fig. 5) following the guidelines provided during the workshops. The simulated symposium 
program consisted in an introduction from the instructor, three talks $(20 \mathrm{~min}$ each including questions from the audience) and a coffee break. STRI scientists and staff attended the meeting. Students dressed professionally for the meeting and took the activity very seriously.

After the role-playing activities, students reflected about this experience and the NOS in their blogs. Finally, students had a conversation via Skype with the only Panamanian formally trained in paleontology so far. She talked about her personal experience becoming a scientist and students asked her questions about how to become an international graduate student.

\section{Assessment}

The course started with an anonymous evaluation to assess students' basic knowledge on paleontology and general biology. This was done so that I could address problematic themes in the course, misconceptions and gaps in their knowledge. Questions included what is: paleontology, a fossil, a species, a population and extinction. I also asked students to provide an estimated age for the formation of the earth, the universe, life on earth, the extinction of dinosaurs and the first humans. This evaluation evidenced that students started the class with a very basic understanding of paleontology. However, they had a striking gap of knowledge in more specific subjects (e.g. the concept of species and the age of the most important event in life's history). These gaps were addressed throughout the course (see Additional file 1).

Other assessments took place to evaluate students' learning during the course (Fig. 6). The following activities and criteria were used as a basis for determining grades (rubrics were not used):

- Readings: students' understanding of the main concepts addressed in the articles was evaluated in every session with a one-question quiz. Questions varied depending on the article and intended to assess whether or not the student had read the paper and understood the concepts. Quizzes had the lowest grade scores (Fig. 6) reflecting problems understanding the readings. This can be due to the fact that arti- cles were mostly in English, adding a further level of difficulty to Spanish-speaking students.

- Discussion engagement: students' participation in the class discussions of the papers was evaluated in every session. This was assessed by giving points every time a student gave an opinion, or asked a question in the discussion. Most of the time, all students participated (Fig. 6).

- Wikis: students' ability to define and connect different concepts was evaluated in their wiki entries. Every student was expected to define 10 concepts per session (two geology sessions) and connect them to earn full credit. All students completed this assignment; however, in a few cases, they provided less than 10 definitions (Fig. 6).

- Blogs: students' ability to reflect on their own learning was assessed in their blogs. After each paleontology session, I read their entries and evaluated if they had provided a thoughtful description of their learning process. Superficial posts (e.g. only saying they enjoyed the class) did not qualify as a reflective post. Such types of posts occurred only at the beginning of the class. In general, students were found to have truly reflected on their own learning in their blogs (Fig. 6).

- Research project: students' ability to apply the concepts learned to real-life situations using research skills was evaluated by assessing (Fig. 6):

- Entries in their field-books: I evaluated if they provide a detailed description of their observations and ideas. Students struggled with this in their first field trip but for their second trip, they all obtained full credit in this evaluation.

- Performance in the peer-review process: I assessed if they were actively and critically participating in their roles as "reviewers" or "editors". This was counted towards their grade in engagement in discussion (see above).

- The written research project (RP written) and project presentations (RP oral): I evaluated if they returned an adequate manuscript and delivered an

\begin{tabular}{|c|c|c|c|c|c|c|c|c|c|c|}
\hline & $\begin{array}{l}\text { Engagement } \\
\text { in discussion }\end{array}$ & $\begin{array}{c}\text { Midterm } \\
1\end{array}$ & $\begin{array}{c}\text { Midterm } \\
2\end{array}$ & $\begin{array}{l}\text { Wiki/ } \\
\text { Blog }\end{array}$ & $\begin{array}{l}\text { Field- } \\
\text { book }\end{array}$ & Quizzes & $\begin{array}{l}\text { RP } \\
\text { written }\end{array}$ & $\begin{array}{l}\mathrm{RP} \\
\text { oral }\end{array}$ & $\begin{array}{l}\text { Final } \\
\text { exam }\end{array}$ & Total \\
\hline Weight & $5 \%$ & $10 \%$ & $10 \%$ & $10 \%$ & $5 \%$ & $5 \%$ & $10 \%$ & $10 \%$ & $35 \%$ & $100 \%$ \\
\hline Class Average & $96 \%$ & $85 \%$ & $70 \%$ & $84 \%$ & $81 \%$ & $61 \%$ & $100 \%$ & $100 \%$ & $98 \%$ & $90 \%$ \\
\hline
\end{tabular}


adequate oral presentation following the guidelines provided (see "Implementation" section).

Students were highly engaged in the research section of the course and they all obtained full credit (Fig. 6).

- Integration (exams): students' ability to integrate the concepts learned was evaluated in two mid-term exams and a final exam (Additional file 1). Even though the midterms had relatively low class-average scores, students did very well in the final exam (Fig. 6). This trend suggests that students were able to better understand the content as they completed additional activities (e.g. research section and role playing).

The course ended with an anonymous course evaluation, in which students rated (i.e. excellent, average or poor) the course strategies and content. Students overwhelmingly rated this course as excellent. However, $20 \%$ thought that the field trips were average. Students had also space to comment on what they liked the most, what they did not like, and to provide suggestions for future courses. Students mostly like the stimulation of critical thinking and authentic learning, they didn't like the fact that this was a time-consuming course and complained about the reading load, especially since it was in English. Finally they suggested having more field trips and fewer readings.

\section{Students' Engagement with Paleontology}

Because the specific objectives of this course were inspired by the necessity to engage young Panamanians with paleontology (Fig. 1), students' blogs were examined to assess their attitudes towards paleontology. It was found that students had eye-opening experiences during the research and science-communication components of the course, in which they were exposed to real-life situations. As demonstrated in the reflective blogs, most students started this course with low expectations and found the course content particularly challenging. However, as they participated in the role-playing activities, they claimed to have found quite eye-opening the fact that it is possible to make fossil discoveries in their own country, and that they were able to both create and communicate knowledge on their own. This course resulted in two students expanding their class projects to their senior thesis. Most importantly, one of them published her research in a scientific journal (Vasquez and Pimiento 2014) and now intends to pursue a career in paleontology.

\section{Recommendations and Future Directions}

Even though there is a large body of literature on the effectiveness of online vs. face-to-face activities (e.g. US
Department of Education 2010; Graham 2013) future courses should include a quantitative assessment on the success of the strategies used in terms of students' cognitive gains. Similarly, a systematic assessment of students' blogs throughout the course would allow measuring changes in students' attitudes towards paleontology as they are engaged in the different activities. An external evaluator should conduct such assessment so that students' input is objectively coded and interpreted. Since the objective of this course is to engage students with paleontology, a long-term survey could be used to assess the impact that this course had in students' careers. Furthermore, course objectives focused on students' skills should be added to this course so that it is possible to have a higher and measurable impact on local capacity. With regards to the course content and strategies, more field trips should be added and students' presentations of their research projects could be streamed and shared with other paleontology classes around the world.

\section{Conclusion}

The design and implementation of this course shows that paleontology can be effectively taught in a blended course with a design grounded in the CoI. Furthermore, this work demostrates that learning experiences can be engaging (encouraging students to study paleontology in their own country) when the content is related to students' realities, and when they can apply research skills to real-life situations.

\section{Author details \\ ${ }^{1}$ Florida Museum of Natural History, University of Florida, Gainesville, FL 32611, USA. ${ }^{2}$ Department of Biology, University of Florida, Gainesville, FL 32611, USA. ${ }^{3}$ Smithsonian Tropical Research Institute, Box 2072, Balboa, Panama. ${ }^{4}$ Paleon- tological Institute and Museum, University of Zurich, 8006 Zurich, Switzerland.}

\section{Acknowledgements}

Financial support was provided by the NSF (EAR 0418042, PIRE 0966884) and STRI. Special thanks to S. Kumar and B. MacFadden for their advice and guidance; to J. Velez-Juarbe and J. N. Griffin for their revising an early manuscript; to C. Jaramillo, N. Gomez, C. Vergara and the University of Panama for their support; and finally, many thanks to the guest speakers, mentors, and workshop participants: A. Rincon, A. Cárdenas, F. Rodríguez, C. De Gracia, F. Moreno, C. Moreno, J. Ortiz, O. Rodriguez and F. Herrera.

Compliance with Ethical Guidelines

\section{Competing Interests}

The author declares that he has no competing interests.

\section{Additional File}

Additional file 1. Concepts assessment. Two mid-term exams and one final exam.

Received: 20 April 2015 Accepted: 17 September 2015

Published online: 29 September 2015 


\section{References}

Benton MJ, Harper DAT. Introduction to paleobiology and the fossil record. Chapter 1: paleontology as a science. Chichester: Wiley-Blackwell; 2009.

Bloom BS, Englehart MD, Furst EJ, Hill WH, Krathwohl D. Taxonomy of educational objectives: cognitive domain. New York: McKay; 1956.

Cadena E, Bourque JR, Rincon AF, Bloch JI, Jaramillo CA, Macfadden BJ. New turtles (Chelonia) from the late Eocene through late Miocene of the Panama Canal Basin. J Paleontol. 2012;86:539-57.

Coulson A, Wendt S, Rice J, Nakamoto J. Evaluation of the MIND Research Institute's spatial-temporal math (ST Math) program in California. California: MIND Research Institute; 2014

Davis SJ, Connolly A, Linfield E. Lecture capture: making the most of face to face learning. Eng Educ J High Educ Acad Eng Subj Cent. 2009;4:4-13.

Demetriadis S, Pombortsis A. E-lectures for flexible learning: a study on their learning efficiency. Educ Technol Soc. 2007;10:147-57.

Fierstine HL. A new marlin, Makaira panamensis, from the Late Miocene of Panama. Copeia. 1978;1978:1-11.

Folley D. The lecture is dead long live the e-lecture. Electr J e-Learn. 2010;8:93-100.

Garrison DR, Arbaugh JB. Researching the community of inquiry framework: review, issues, and future directions. Internet High Educ. 2007;10:157-72.

Garrison DR, Kanuka H. Blended learning: uncovering its transformative potential in higher education. Internet High Educ. 2004;7:95-105.

Garrison DR, Vaughan ND. Blended learning in higher education: framework, principles, and guidelines. San Francisco: Jossey-Bass; 2008.

Glaubrecht M. On "Darwinian Mysteries" or molluscs as models in evolutionary biology: from local speciation to global radiation. Am Malacol Bull. 2009:27:3-23.

Gottesman AJ, Hoskins SG. CREATE Cornerstone: introduction to scientific thinking, a new course for STEM-interested freshmen, demystifies scientific thinking through analysis of scientific literature. CBE Life Sci Educ. 2013;12:59-72.

Graham CR. Emerging practice and research in blended learning. In: Moore MG, editor. Handbook of distance education. New York: Routledge; 2013. p. 333-50.

Halic O, Lee D, Paulus T, Spence M. To blog or not to blog: student perceptions of blog effectiveness for learning in a college-level course. Internet High Educ. 2010;13:206-13.

Harrison M, Dunbar D, Ratmansky L, Boyd K, Lopatto D. Classroom-based science research at the introductory level: changes in career choices and attitude. CBE Life Sci Educ. 2011;10:279-86.

Herrera F, Manchester SR, Jaramillo C. Permineralized fruits from the late Eocene of Panama give clues of the composition of forests established early in the uplift of Central America. Rev Palaeobot Palynol. 2012;175:10-24

Hoskins SG, Stevens LM. Learning our L.I.M.I.T.S.: less is more in teaching science. Adv Physiol Educ. 2009;33:17-20.
Kays J. Digging Panama. Explore magazine. Research at the University of Florida, spring; 2014. p. 15-23.

Kirby MX, Jones DS, MacFadden BJ. Lower miocene stratigraphy along the Panama canal and its bearing on the central american peninsula. PLoS One. 2008;3:e2791.

Lederman NG. Students' and teachers' conceptions of the nature of science: a review of the research. J Res Sci Teach. 1992;29:331-59.

Lederman NG. Delineating classroom variables related to students' conception of the nature of science. Dissertation abstracts international, 45, 483A. University Microfilms No. 84-10, 728. 1983.

MacFadden BJ. Extinct mammalian biodiversity of the ancient New World tropics. Trends Ecol Evol. 2006;21:157-65

Michaels S, Shouse AW, Schweingruber HA. Ready, set, science: putting research to work in K-8 science classrooms. Washington, DC: National Academy Press; 2008.

ODea A, Rodríguez F, De Gracia C, Coates AG. Patrimonio Paleontológico. La paleontología marina en el Istmo de Panamá. Canto Rodado. 2007:2:149-79.

Pane JF, Griffin BA, McCaffrey DF, Karam R, Daugherty L, Phillips A. Does an algebra course with tutoring software improve student learning? Santa Monica, CA: RAND Corporation, 2013. 2013. http://www.rand.org/pubs/ research_briefs/RB9746.

Pimiento C, Ehret DJ, MacFadden BJ, Hubbell G. Ancient nursery area for the extinct giant shark Megalodon from the Miocene of Panama. PLoS One. 2010;5:e10552.

Pimiento C, González-Barba G, Ehret DJ, Hendy AJ, MacFadden BJ, Jaramillo C. Sharks and rays (Chondrichthyes, Elasmobranchii) from the late Miocene Gatun formation of Panama. J Paleontol. 2013;87:755-74.

Richardson W. Blogs, wikis, podcasts, and other powerful web tools for classrooms. California: Corwin Press; 2010

Schwartz L, Clark S, Cossarin M, Rudolph J. Educational wikis: features and selection criteria. Int Rev Res Open Distance Learn. 2004;5:1-6.

Tselios NK, Daskalakis S, Papadopoulou M. Assessing the acceptance of a blended learning university course. J Educ Technol Soci. 2011;14:224-35.

U.S. Department of Education. Office of planning, evaluation, and policy development, evaluation of evidence-based practices in online learning: a meta-analysis and review of online learning studies. Washington, DC. 2010

Valderrama JO. Principales Aspectos sobre la Preparación de un Artículo para ser Publicado en una Revista Internacional de Corriente Principal. Inf Tecnol. 2005;16:3-14.

Vasquez S, Pimiento C. Sharks and rays from the Tonosi formation (Eocene of Panamá). Cent Am J Geol. 2014;51:165-9.

\section{Submit your manuscript to a SpringerOpen ${ }^{\circ}$ journal and benefit from:}

- Convenient online submission

- Rigorous peer review

- Immediate publication on acceptance

- Open access: articles freely available online

- High visibility within the field

- Retaining the copyright to your article

Submit your next manuscript at $>$ springeropen.com 